DOI: https://doi.org/10.15688/jvolsu4.2016.4.14

UDC 32.01

Submitted: 18.04 .2016

LBC 66.0

Accepted: 19.07.2016

\title{
ANALOGUE FORMS OF THE CIVIL SOCIETY (EXEMPLIFIED BY THE ISLAMIC COUNTRIES)
}

\author{
Grigoriy M. Barashkov
}

National Research Saratov State University named after N.G. Chernyshevsky, Saratov, Russian Federation

\begin{abstract}
The article deals with the analogue forms of civil society in the Islamic countries of the South. The author analyzes the formation and development of the civil society in this region of the world, its specifics and peculiarities. The author also shows that burgeoning civil society models of non-western area have their own specific features, which are determined by a unique way of civilizational development and by significant impact of the religious factor. The present research brings up a methodological novation - an analogous civil society. According to this novation, the developing political system (which takes part in civilizational competition with other systems and tries to use their historical experience and accumulated resources explicitly, for example, by attracting ideas, technologies, investments, or implicitly - by creating the same resources through modernization and social mobilization) does not imply an organic link between ideologically reflected meaning of this system's existence, the forms of such existence, and the main institutions' functionality. Moreover, this smoothness is not very important and desirable for the analogue system or its components. The meaning of such system's existence is using the forms, principles, mechanisms, elaborated through historical development of social and political systems for their own specific purposes, for the sake of diametrically opposed goals that sometimes are not very detailed.

Key words: analogue model, civil society, democracy, democratization, modernization, traditionalism, religious factor, Islam.

УДК 32.01

Дата поступления статьи: 18.04.2016

ББК 66.0

Дата принятия статьи: 19.07.2016
\end{abstract}

\section{АНАЛОГОВЫЕ ФОРМЫ ГРАЖДАНСКОГО ОБЩЕСТВА (НА ПРИМЕРЕ СТРАН ИСЛАМСКОГО АРЕАЛА)}

\author{
Григорий Михайлович Барашков \\ Саратовский национальный исследовательский государственный университет им. Н.Г. Чернышевского, \\ г. Саратов, Российская Федерация
}

\footnotetext{
Ан Анотация. В статье рассматриваются аналоговые формы гражданского общества в странах Юга на 尺े примере стран «коренного» ислама. Анализируется становление и развитие гражданского общества в этом ¿ регионе мира, его специфика и характерные черты. Показано, что формирующиеся модели гражданского общества незападного ареала обладают собственными, специфическими чертами, определяемыми особым о̊ характером цивилизационного развития этих стран, существенным влиянием религиозного фактора. В ис見 следовании введена методологическая новация - аналоговое гражданское общество, которая подразумева‡ ет, что в развивающейся политической системе, участвующей в цивилизационной конкуренции с другими (3) системами, исторический опыт и накопленные ресурсы которых она намеревается использовать в своих
} 
интересах прямо, например, путем привлечения идей, технологий, инвестиций, или косвенно (создавая такие же ресурсы у себя путем, например, модернизаций и социальных мобилизаций), изначально не предусмотрено органической связи между идеологически отрефлексированным смыслом существования этой системы, формами этого существования и функциональностью основных институтов. Более того, такая органичность не является для аналоговой системы в целом или в отдельных ее составляющих принципиально важной и желательной. Смысл существования такой системы состоит в том, чтобы использовать формы, принципы, механизмы, наработанные в ходе исторического развития одних социально-политических систем, для решения именно их очень конкретных и специфических задач и совершенно других задач, часто даже не очень конкретных.

Ключевые слова: аналоговая модель, гражданское общество, демократия, демократизация, модернизация, традиционализм, религиозный фактор, ислам.

На первый взгляд, вопрос о наличии и функционировании гражданского общества в незападном ареале исключает сколько-нибудь реальные мотивы для его постановки в исследовательском плане ввиду определенных условий развития и становления данных обществ, особенно учитывая евро-американское происхождение и довольно рыхлое содержание самой концепции гражданского общества, разнообразие его моделей, характеристик гражданских организаций, сфер и направлений их деятельности, отношений с государством, рынком и т. д. Могут ли гражданские общества существовать вне западной цивилизации? Некоторые исследователи в этом сомневаются ввиду связи этого понятия с особой исторической траекторией западных обществ. Построение социальных отношений на общинной, этнической или религиозной основе, как и смешение государственной и частной сфер, вроде бы должно препятствовать развитию гражданских обществ в полном смысле слова. Интенсивность дискуссий по этому вопросу не помешала появлению новых акторов на Юге и Востоке, принадлежность которых к гражданскому обществу вряд ли может быть оспорена [8].

Цель данной статьи - показать наличие существования гражданского общества не только в странах Запада, но и в других регионах мира, в частности в странах исламского ареала. При исследовании общей проблематики гражданского общества вряд ли можно исходить из существующей какой-то единой «нормативной» его модели, как это делают некоторые исследователи [13, с. 32-33]. Это объясняется тем, что в мире сложно найти страны с комплексом абсолютно идентичных культурно-исторических, экономических, поли- тических и иных условий развития, которые бы укладывались в некое лекало. Есть некий набор признаков «идеального» гражданского общества, в наибольшей мере существующий в экономически и демократически развитых государствах. Страны догоняющего развития, в том числе страны Юга, с разной степенью настойчивости пытаются освоить этот набор, который, накладываясь на местную специфику, порождает своеобразные формы гражданских отношений.

Существует мнение, что препятствием для становления гражданского общества в странах Юга являются два фактора. Во-первых, западное происхождение этого феномена. Во-вторых, существенное различие в характере формирования общественных организаций, которые на Западе образуются на добровольной основе, а в странах Юга - по аскриптивному принципу, то есть строго в соответствии с социальными характеристиками каждого вступающего в организацию (пол, этническая принадлежность, имущественное положение и т. д.). Между тем в незападных странах, включая страны Юга, гражданское общество пробивает себе дорогу, привнося в свое содержание элементы, определяемые цивилизационной природой населения того или иного региона. Вполне успешное гражданское общество существует в целом ряде регионов мира, отличающихся от западных по своим цивилизационным моделям (Япония, Южная Корея, Индия, ЮАР и др.).

В странах незападного ареала формируются модели гражданского общества, которые со временем приблизятся по некоторым параметрам к «западному образцу», но в то же время будут обладать собственными специфическими чертами, определяемыми осо- 
бым характером цивилизационного развития этих стран. Феномен цивилизационной специфики в русле глобальных процессов стал темой научных дискуссий и публикаций. Так, исследователь В.С. Степин считает, что категории «гражданское общество», «правовое государство», «права человека» принадлежат культуре одного типа цивилизации. Их нельзя применять к традиционалистскому обществу. Это связано с тем, что, по его мнению, личность в традиционалистском обществе определяется через семейно-корпоративные и производственно-корпоративные связи. Это личность только потому, что является частью корпорации, сословия, касты, общины. Он выразил сомнение в том, что права человека могут быть «в традиционной культуpe» $[11$, c. 23,26$]$.

Процессы становления гражданского общества в странах Юга, как и в других государствах и регионах мира, отмечены своими закономерностями и особенностями. Вместе с тем само понятие «гражданское общество» в известной мере достаточно аморфно. В разное историческое время оно имело различные, порой чуть не взаимоисключающие толкования. В связи с этим оптимальным направлением анализа феномена гражданского общества в странах Юга можно считать исследование процессов формирования определенного набора его признаков и проявлений их жизнедеятельности на современном этапе. Ввиду неравномерности развития различных социумов эти проявления имеют свою национальную, религиозную и иную специфику.

В наиболее общей форме существующая ныне концепция гражданского общества характеризует его как один из трех полюсов в структуре социума, который, отражая и защищая интересы граждан, оказывает давление на два других полюса - власть и рынок. Генезис такого общества проходит через активность граждан, создающих при наличии определенных политических, экономических и социальных условий различные организации некоммерческого, неправительственного толка, стабильное функционирование которых обеспечивает демократизацию общества.

Анализ традиционных обществ позволяет сделать вывод о возникновении в них особой среды, сложившейся в результате синте- за традиционных и западных культурных начал. Этот своеобразный симбиоз проявляется прежде всего в сфере политической культуры. Причем чем нагляднее и очевиднее становятся признаки вестернизации политической жизни в данных регионах, тем мощнее сказывается скрытое влияние традиционных элементов. Профессор Н.И. Шестов в своей монографии, исследуя политическую культуру, отмечает, что на современном этапе на передний план в ней все более выходят универсальные, «общечеловеческие» идеи и ценности. «Но не они, в конечном итоге, определяют специфику развития национального политического процесса, - подчеркивает исследователь. - Они, скорее, создают некоторый “цивилизационный фон”, в сравнении с которым корректируется структура и содержание идейного обеспечения современных политических процессов в различных государствах. В гораздо большей степени упомянутая специфика предопределена массивом так называемых социально-мифологических представлений о политической реальности. Они, эти представления, создают неповторимую историческую и национальную окраску политической культуры и, в известной мере, ее своеобразное внутреннее качество» $[12$, с. 3]. Сказанное как нельзя точно характеризует политические процессы в традиционных обществах, привнося в них особенность и неповторимость, в частности, в формировании и функционировании гражданского общества.

Возникновение гражданских организаций в странах Юга определялось рядом внутренних и внешних факторов. К первым относится ослабление государств в отправлении их основных социальных функций, то есть ситуация, в которой эти организации становились для населения некой альтернативой государству; рост так называемых промежуточных элит, способствующий подъему разного рода ассоциаций. Ко вторым можно отнести окончание межблоковой «холодной войны», расширившее политическое пространство для организаций гражданского общества, увеличение международных неправительственных организаций, создававших свои отделения в развивающихся странах, а также международной помощи странам Юга в обход государственных структур. 
Демократизация политических режимов, рост гражданской активности не обошли стороной и арабские страны. Многие гражданские организации или предстают здесь в роли партнеров государства, или делают упор на вопросах защиты прав человека. Специфической чертой социально-политической ситуации в этом регионе является довольно сильное влияние религиозного (исламского) фактора, что нередко отражается на внутренней структуре и функциональности гражданских организаций. В Египте, Тунисе - странах так называемой арабской весны - исламские организации, например, относят себя к гражданскому обществу. Но «исламизированной» концепции гражданского общества, практически неизбежной в мусульманских странах, довольно активно и небезуспешно противостоит его «светская», демократическая трактовка, и столкновение этих двух течений во многом характеризует идейную атмосферу общественной жизни в арабском мире.

Говоря об основополагающих характеристиках стран исламского ареала Юга, современные исследователи точно также выделяют ряд наиболее существенных свойств их политической культуры, институционального дизайна политических отношений вообще и гражданских отношений в частности. Следует отметить, что в общественном сознании мусульман религиозное мировоззрение является господствующим. Ислам выступает не просто религией, он формирует общественный уклад, влияет на политико-правовые отношения. По меткому замечанию К. Маркса, «религия есть общая теория арабского мира, его энциклопедический компендиум, его логика в популярной форме, его спиритуалистический l'honneur, его энтузиазм, его моральная санкция, его торжественное восполнение, его всеобщее основание для утешения и оправдания» [7]. К любым нововведениям, к любому новому веянию здесь подходят прежде всего с позиций религии, насколько то или иное мнение или действие соответствует или противоречит религиозным канонам.

Концепция гражданского общества зиждется на индивидуальном участии граждан в социальном развитии. Религия обладает мощной мобилизационной силой такого участия. Мусульмане в большей степени, чем христи- ане, непосредственно (индивидуально) общаются с Богом, да и сама религия возникла не в государстве и не связана с конкретной системой власти.

Население ищет в религии выход из тяжелого социально-экономического положения. В то же время правящие режимы, оппозиционные партии и движения, неправительственные организации рассматривают ее как наиболее эффективное средство вовлечения населения в общественную жизнь, так как освященные религией политические лозунги ближе и понятнее народным массам. Часто именно ислам становится знаменем борьбы за перемены. В этой связи следует отметить исследователя Д. Аптера, который видел в религии одну из фундаментальных возможностей политической мобилизации [1].

По мнению исследователя А. Малашенко, в отличие от ислама, в остальных религиях фундаменталистские проявления носят ограниченный во времени и пространстве характер. В одних случаях они сдерживаются секуляристским характером общества, в других - замыкаются на частных национальных или религиозных проблемах. «И только исламизм оказался геокультурным и геополитическим феноменом, интегрирующим мусульманское сообщество, оказывающим влияние не только на его внутреннее сознание, но и на его отношение с остальным миром» [6, с. 65-66].

Образ религиозной альтернативы присутствует во всех мусульманских странах в качестве некой надежды, светлой мечты. Даже процессы демократизации в этих странах ведутся на фоне исламизации политической жизни. По образному выражению исследователя М. Сергеева, «всякое политическое действо становится религиозно окрашенным, а все, что имеет отношение к религии, приобретает политический оттенок» $[10$, с. 203].

Эти страны, по устоявшемуся сегодня мнению исследователей, характеризуются тем, что исламская традиция десятки лет синтезировалась с иными, прежде всего европейскими культурными и правовыми традициями. Тенденции этого синтеза наиболее ярко представлены в странах «коренного» ислама, расположенных в Северной Африке, Ближнем и Среднем Востоке. Хотя государство в исламе рассматривается как главный инструмент 
при исполнении божественного закона (шариата), его конкретная форма и организация не регламентируются. Поэтому мусульмане в современном мире с большим успехом, нежели представители других социокультурных традиций, могут использовать формы организации власти неисламского происхождения, в том числе демократические инструменты, если они не нарушают исламских норм и ценностей. Исламисты сходятся в том, что высшая власть принадлежит Богу, а право применять его законы передано общине верующих (умме). Глава общины или государства - это лишь представитель общины, которая избирает, контролирует и при необходимости низлагает его $[4$, с. 96$]$.

Известный российский исследователь политического ислама Г. Джемаль считает, что в истории мусульманских стран ислам предстает как гражданское общество в абсолютном смысле. Община пророка Мухаммеда в Медине, по его мнению, была не государством, а «самоорганизующимся, самоуправляющимся братством, над которым были только авторитет и воля Аллаха, передаваемая через его Посланника» [3]. Г. Джемаль вводит термин «самодостаточная общность», основой которой всегда, даже в модернистском социуме, выступает моральный императив. Для мусульманина такой императив, по его мнению, состоит в том, чтобы не позволять лишить себя статуса инструмента божественного провидения, то есть не лишаться исторической ответственности, субъективности. А ведь именно в многообразии сетевой структуры неправительственных организаций реализуется гражданское общество как коллективный субъект, определяющий в конечном счете историко-цивилизационный курс.

Чего не объясняет этот устоявшийся подход, так это причины, по которым в сегодняшнем ареале «коренного» ислама, где с наибольшим успехом осуществлялся этот самый синтез цивилизационных традиций Запада и Востока, страны Юга оказались фактически во главе процесса исторического реванша исламского традиционализма, демонстрируя революционные подходы к обеспечению такого реванша на уровне и социальной, и государственной организации, а также нежелание следовать принципам религиозной, этнической, политической толерантности, на которых, по идее, должно быть основано не только «синтетическое» гражданское общество, а вообще любое гражданское сообщество как таковое. Получается, что «синтез» вроде бы был и для него были предпосылки в самой структуре социально-политической и экономической организации исламских обществ, но результаты этого синтеза имели однобоко традиционалистский характер.

Современные богословы, сторонники сотрудничества религии с гражданским обществом, полагают, что ислам является социообразующей религией, в которой общественные отношения наряду с основными правовыми положениями подвержены строгой регламентации уже на уровне божественного откровения, то есть выступают в качестве некоего императива, обязывающего создавать общественную жизнь на основе именно исламских принципов, а не на выработке и согласовании общественно-правовых концепций.

Вместе с тем при ответе на вопрос о возможности участия мусульман в институтах гражданского общества современные исследователи приходят к разным выводам: от неизбежности конфликта между классическим исламом (особенно представленным в своих политических формах) и гражданским обществом до осуществления их мирного взаимодействия.

Представители либерального крыла умеренных исламистов, определяя условиями существования гражданского общества частную собственность, свободную рыночную экономику, гражданские свободы, полагают, что социально-политическая сфера гражданского общества, включающая в себя общественнополитические организации и движения, а также различные формы гражданской активности граждан в виде митингов, демонстраций, собраний, органов местного самоуправления, независимых средств массовой информации, не противоречит исламу.

Возможно, что внутренняя противоречивость исламского общества заложена в том, что Коран устанавливает абсолютный авторитет Бога (2:209) [5, с. 49-50], что предполагает наличие веры. Вся арабская история пронизана конфликтом «откровение - цивилиза- 
ция». Для цивилизационного развития религиозная составляющая является важным, но не единственным источником самоидентификации. «Человеческое» одерживает в ней вверх над «божественным», но при этом если в христианстве возможно отлучить от церкви, то в исламе такое невозможно в принципе.

Умеренные исламисты полагают, что между исламским обществом и гражданским обществом не может быть серьезных противоречий. Религия в исламском обществе, пронизывающая все сферы бытия, служит для них одним из факторов существования человеческого общества, где главным является человек с его повседневным и историческим бытием. Разница состоит лишь в точках зрения на аспекты цивилизации. Показательно, что в возникающем в этом случае «диалоге цивилизаций» роль его главных участников играют представители исламской интеллигенции, общественных групп и т. д., то есть тех самых социальных сегментов, которые в принципе характерны для гражданского общества либерального типа.

Своеобразие политической культуры арабов заключается в почитании лидера. Вождизм является частью их политических приоритетов. В таком случае существенным может оказаться не столько институциональная и правовая легитимность, сколько энтузиазм и доверие масс. В силу этого значение сильной личности в качестве стимулирующего фактора развития гражданского общества в арабских странах особенно велико. Именно поэтому становится возможной так называемая демократизация сверху, дозированная демократия.

В научной литературе существуют две основные трактовки гражданского общества. Первая связывает его с государственной системой демократического типа, защищающей основные права и свободы личности, в силу чего традиционное общество эволюционирует в гражданское. Роль такого «катализатора» демократических процессов в арабских странах может взять на себя «просвещенный» лидер. Согласно второй трактовке гражданское общество - это образование независимых от государства множественных по форме и целям ассоциаций и групп. Именно такой тип формирующегося гражданского общества на данный момент характерен для арабских государств. Ему свойственна отдельность гражданского общества от государственно-политической системы с акцентировкой оппозиционной роли в случае дрейфа властных структур к авторитарному правлению.

Еще одной особенностью политической культуры в арабских странах является тот факт, что индивидуализм, представляющий собой основу гражданского общества западных стран, до некоторой степени чужд арабам. В арабских странах глубоко ощущение общности судьбы их народов. Арабы осознают себя частью двух крупных общностей: общей арабской культуры и истории, с одной стороны, и огромной мусульманской уммы с другой. Кроме того, «шариат основан на идее обязательств, возложенных на человека, а не на правах, которые он может иметь» [2, c. 83].

Индивид в исламе выступает носителем субъективного права прежде всего в сфере семьи, собственности и других сферах частного интереса. В остальных социальных сфеpax он представлен, как правило, в качестве носителя обязанностей по отношению к Богу, исламской умме и т. д. Иными словами, в исламском мире несколько иное, чем в западном, соотношение между свободами и обязанностями личности.

Однако в современном мире соблюдение прав личности становится критерием цивилизованности стран. В этой области сложился определенный международный стандарт, основу которого составили Всеобщая декларация прав человека 1948 г., а также Пакты о социальных, экономических, политических и культурных правах 1966 года. Арабские документы аналогичного характера представлены Арабским пактом о правах человека, Bceобщей исламской декларацией прав человека, а также Проектом исламской конституции. Анализ этих актов с точки зрения влияния на них ислама свидетельствует о том, что мусульманская форма используется лишь как средство закрепления прав и свобод, содержащихся во Всеобщей декларации прав человека и иных актах $\mathrm{OOH} \mathrm{о} \mathrm{правах} \mathrm{человека.}$ Характерно наличие в арабских странах множества соответствующих организаций, например, Тунисская лига защиты прав человека, 
Марокканский консультативный совет по правам человека и т. д.

Некоторые исследователи, подвергая сомнению возможность становления гражданского общества в странах Юга, указывают на недостаточное развитие у этих народов «гражданского духа». Однако обилие создаваемых в арабских странах неправительственных организаций, ассоциаций, обществ и т. п. свидетельствует о необоснованности такого мнения.

Понимание необходимости перемен стало приметой современного развития арабского мира. Перемены невозможны без демократических изменений, которые тесным образом связаны с гражданским обществом. Демократическое развитие создает условия и способствует становлению и активизации деятельности гражданского общества, а оно, в свою очередь, защищает права и завоевания, достигнутые в результате осуществления реформ. Введение политического плюрализма, активизация участия народных масс в социально-политическом процессе, привлечение представителей всех слоев населения для создания новых политико-правовых основ демократического общества - все это призвано заложить основы гражданского общества.

Однако при этом следует учитывать, что политические процессы, происходящие в этих странах, и силы, участвующие в них, представляют собой своеобразные живые организмы. Они подвергаются влияниям извне, внутренним колебаниям и вынуждены учитывать внешнюю и внутреннюю конъюнктуру, соответствовать расстановке сил и в своей стране, и за рубежом. Поэтому трудно внедрить и вырастить функционирующие демократические институты на изменчивой социальной почве. Как справедливо отмечает исследователь О. Рой, неправительственным организациям и международным институтам следует работать с той социальной тканью, которая уже существует и принимается местным населением, «а не придумывать для общества программы, плохо приспособленные к местным нуждам и ожиданиям» [9].

Таким образом, гражданское общество в странах исламского ареала не является какимлибо чужеродным элементом, привнесенным извне. Существование гражданского общества не противоречит исламским религиозным догматам и поэтому вполне успешно функционирует в политическом пространстве мусульманских стран, представляя собой некий синтез из «западного образца», дополненного собственным специфическим содержанием, определяемым культурно-историческим и цивилизационным развитием этих стран.

\section{СПИСОК ЛИТЕРАТУРЫ}

1. Аптер, Д. Политика модернизации / Д. Аптер. - Электрон. текстовые дан. - Режим доступа: http://www.psyoffice.ru/6-567-politicheskajamodernizacija.htm (дата обращения: 13.07.2013). Загл. с экрана.

2. Гали, Б. Б. Пугь Египта в Иерусалим / Б. Б. Гали. - М. : Книжный дом газеты Труд, 1999. - 416 с.

3. Джемаль, Г. Контрудар / Г. Джемаль. - Электрон. текстовые дан. - Режим доступа: http://www. kontrudar.ru/ (дата обращения: 02.04.2010). - Загл. с экрана.

4. Комар, Ю. И. Ислам, демократия и гражданское общество / Ю. И. Комар // Афро-азиатский мир: Проблемы цивилизационного анализа. - М. : ИНИОН РАН, 2004. - Вып. 2. Региональные цивилизации. - С. 91-96.

5. Коран. - М. : АНС-Принт, 1990.-512 с.

6. Малашенко, А. Исламская альтернатива и исламский проект / А. Малашенко. - М. : Весь Мир, 2006. $-221 \mathrm{c}$.

7. Маркс, К. К критике гегелевской философии права / К. Маркс. - Электрон. текстовые дан. Режим доступа: http://www.k2×2.info/filosofija/ sobranie_sochinenii_tom_1/p5.php (дата обращения: 08.04.2016). - Загл. с экрана.

8. Потемкин, Ю. В. К вопросу о «гражданизации» африканских обществ / Ю. В. Потемкин. Электрон. текстовые дан. - Режим доступа: http:// kunstkamera.ru/files/lib/978-5-88431-148-7/978-588431-148-7_05.pdf(дата обращения: 08.04.2016).Загл. с экрана.

9. Рой, О. Гражданское общество в мусульманском мире: современные взгляды / О. Рой. Электрон. текстовые дан. - Режим доступа: http:// www.iis.ac.uk/SiteAssets/pdf/Civil\%20Society\% 20Book\%20Review final\%20and\%20revised $\% 20$ 6_AA_RUS.pdf(дата обращения: 09.09.2013). - Загл. с экрана.

10. Сергеев, М. С. История Марокко. ХХ век / М. С. Сергеев. - М. : Изд-во Институга востоковедения РАН, 2001. -359 с.

11. Степин, В. С. Гражданское общество, правовое государство и право / В. С. Степин // Вопросы философии. - 2002. - № 1. - С. 3-50. 
12. Шестов, Н. И. Политический миф теперь и прежде /Н. И. Шестов. - М. : Олма-Пресс, 2005. - 414 с.

13. Шлихтер, А. А. «Третий сектор» (некоммерческий) и гражданское общество США / А. А. Шлихтер // Мировая экономика и международные отношения. - 2006. - № 12. - С. 24-34.

\section{REFERENCES}

1. Apter D. Politika modernizatsii [Moderni-zation Policy]. Available at: http://www. psyoffice.ru/6-567politicheskaja-modernizacija.htm. (accessed July 13, 2013).

2. Gali B.B. Put Egipta v Ierusalim [Egypt's Way to Jerusalem]. Moscow, Knizhnyy dom gazety "Trud”, 1999. $416 \mathrm{p}$.

3. Dzhemal G. Kontrudar [Counter Strike]. Available at: http://www.kontrudar. ru/. (accessed April 2, 2010).

4. Komar Yu.I. Islam, demokratiya i grazhdanskoe obshchestvo [Islam, Democracy, and Civil Society]. Afro-aziatskiy mir: Problemy tsivilizatsionnogo analiza. Vyp. 2. Regionalnye tsivilizatsii [Afro-Asian World: the Problems of Civilizational Analysis. Iss. 2. Regional Civilizations]. Moscow, Izd-vo INION RAN, 2004, pp. 91-96.

5. Koran [Quran]. Moscow, ANS-Print Publ., 1990.512 p.

6. Malashenko A. Islamskaya alternativa $i$ islamskiy proekt [Islamic Alternative and Islamic World]. Moscow, Ves Mir Publ., 2006. 221 p.
7. Marks K. K kritike gegelevskoy filosofii prava [To the Critics of Hegel's Philosophy of Law]. Available at: http://www.k2 2 2.info/filosofija/ sobranie_sochinenii_tom_1/p5.php. (accessed April 8, 2016).

8. Potemkin Yu.V. K voprosu o "grazhdanizatsii" afrikanskikh obshchestv [To the Issue of "Civilization" of African Societies]. Available at: http:// kunstkamera.ru/files/lib/978-5-88431-148-7/978-5-88431148-7_05.pdf. (accessed April 8, 2016).

9. Roy O. Grazhdanskoe obshchestvo v musulmanskom mire: sovremennye vzglyady [The Civil Society in the Muslim World: Contemporary Views]. Available at: http:/www.iis.ac.uk/SiteAssets/pdf/ Civil $\% 20$ Society $\% 20$ Book $\% 20$ Review final $\% 20$ and $\% 20$ revised\%20_6_AA_RUS.pdf. (accessed September 9, 2013).

10. Sergeev M.S. Istoriya Marokko. XXvek [History of Morocco. The 20th Century]. Moscow, Izd-vo In-ta vostokovedeniya RAN, 2001. 359 p.

11. Stepin V.S. Grazhdanskoe obshchestvo, pravovoe gosudarstvo i pravo [Civil Society, Legal State, and Law]. Voprosy filosofii, 2002, no. 1, pp. 3-50.

12. Shestov N.I. Politicheskiy mif teper i prezhde [Political Myth Now and Before]. Moscow, Olma-Press Publ., 2005. 414 p.

13. Shlikhter A.A. "Tretiy sector" (nekommercheskiy) i grazhdanskoe obshchestvo SShA [The Third Sector (Noncommercial) and Civil Society in the USA]. Mirovaya ekonomika i mezhdunarodnye otnosheniya, 2006, no. 12, pp. 24-34.

\section{Information About the Author}

Grigoriy M. Barashkov, Candidate of Sciences (Politics), Associate Professor, Department of Political Science, National Research Saratov State University named after N.G. Chernyshevsky, Astrakhanskaya St., 84, 410005 Saratov, Russian Federation, Eternity65@yandex.ru.

\section{Информация об авторе}

Григорий Михайлович Барашков, кандидат политических наук, доцент кафедры политических наук, Саратовский национальный исследовательский государственный университет им. Н.Г. Чернышевского, ул. Астраханская, 83, 410005 г. Саратов, Российская Федерация, Eternity65@yandex.ru. 